\title{
Prediction of Stable and Active (Oxy-Hydro) Oxide Nanoislands on Noble-Metal Supports for Electrochemical Oxygen Reduction Reaction
}

Back, Seoin; Hansen, Martin H.; Garrido Torres, Jose A.; Zhao, Zhenghang; Nørskov, Jens K.; Siahrostami, Samira; Bajdich, Michal

\section{Published in:}

ACS Applied Materials and Interfaces

Link to article, DOI:

10.1021/acsami.8b15428

Publication date:

2019

Document Version

Peer reviewed version

Link back to DTU Orbit

Citation (APA):

Back, S., Hansen, M. H., Garrido Torres, J. A., Zhao, Z., Nørskov, J. K., Siahrostami, S., \& Bajdich, M. (2019). Prediction of Stable and Active (Oxy-Hydro) Oxide Nanoislands on Noble-Metal Supports for Electrochemical Oxygen Reduction Reaction. ACS Applied Materials and Interfaces, 11(2), 2006-2013. https://doi.org/10.1021/acsami.8b15428

\section{General rights}

Copyright and moral rights for the publications made accessible in the public portal are retained by the authors and/or other copyright owners and it is a condition of accessing publications that users recognise and abide by the legal requirements associated with these rights.

- Users may download and print one copy of any publication from the public portal for the purpose of private study or research.

- You may not further distribute the material or use it for any profit-making activity or commercial gain

- You may freely distribute the URL identifying the publication in the public portal 


\title{
Prediction of Stable and Active (Oxy-Hydro) Oxide Nanoislands on Noble-Metal Supports for Electrochemical Oxygen Reduction Reaction
}

\author{
Seoin Back, ${ }^{\dagger}$ Martin H. Hansen, ${ }^{\ddagger}$ Jose A. Garrido Torres, $^{\ddagger}$ Zhenghang Zhao, $^{\dagger}$ Jens K. Nørskov, $^{\dagger \neq, \S}$ \\ Samira Siahrostami, $*,+\odot$ and Michal Bajdich $*, \ddagger \subset$ \\ ${ }^{\dagger}$ SUNCAT Center for Interface Science and Catalysis, Department of Chemical Engineering, Stanford University, Stanford, \\ California 94305, United States \\ ${ }^{\ddagger}$ SUNCAT Center for Interface Science and Catalysis, SLAC National Accelerator Laboratory, 2575 Sand Hill Road, Menlo Park, \\ California 94025, United States \\ ${ }^{\S}$ Department of Physics, Technical University of Denmark, Lyngby DK-2800 Kgs, Denmark
}

\begin{abstract}
Developing cost-effective oxygen electrocatalysts with high activity and stability is key to their commercialization. However, economical earth-abundant catalysts based on first-row transition-metal oxides suffer from low electrochemical stability, which is difficult to improve without compromising their activity. Here, using density functional theory calculations, we demonstrate that noble-metal supports lead to bifunctional enhancement of both the stability and the oxygen reduction reaction (ORR) activity of metal (oxy-hydro) oxide nanoislands. We observe a significant stabilization of supported nanoislands beyond the intrinsic stability limits of bulk phases, which originates from a favorable lattice mismatch and reductive charge transfer from

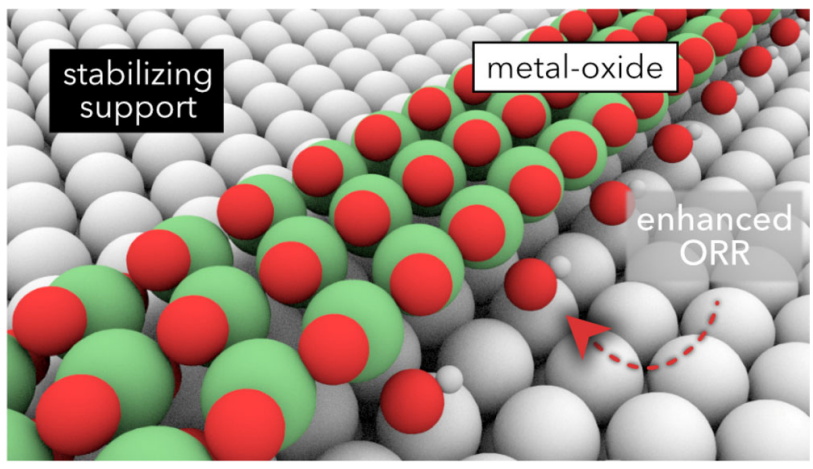
oxophilic supports. We discover that interfacial active sites (located between the nanoisland and the support) reinforce the binding strength of reaction intermediates, hence boosting ORR activity. Considering that both stability and activity lead to discovery of $\mathrm{CoOOH} \mid \mathrm{Pt}, \mathrm{NiOOHIAg}$, and $\mathrm{FeO}_{2} \mid \mathrm{Ag}$ as viable systems for alkaline ORR, we then use a multivariant linear regression method to identify elementary descriptors for efficient screening of promising cost-effective nanoislandlsupport catalysts.
\end{abstract}

KEYWORDS: oxide, oxy-hydroxide, FCC metal supports, density functional theory calculations, oxygen reduction reaction, Pourbaix diagrams, correlation analysis, multivariant linear regression

\section{INTRODUCTION}

The development of new active, stable, and cost-effective alternative catalysts has been of utmost focus in renewable and sustainable future energy technologies such as fuel cells, electrolyzers, and metal-air batteries. ${ }^{1-4}$ In fuel cell cathodes, ${ }^{2,5}$ in particular, innovative materials to replace the state-of-the-art Pt-based catalysts would benefit automotive and stationary applications. ${ }^{6-8}$ Although various successful approaches to increase catalytic activities and reduce $\mathrm{Pt}$ dependency have been proposed, achieving both high activity and stability simultaneously turned out to be challenging without sacrificing other properties. $^{2-4,6-8}$ Therefore, new design principles to improve activity and stability, combined with a theoretical platform that is readily applicable to other catalyst systems or electrochemical reactions are essential.

First-row transition-metal materials have been targeted for various electrochemical reactions because of their abundance, high activity, and tunable morphology. ${ }^{9-13}$ Their (oxy-hydro) oxides have largely been explored as alkaline oxygen evolution reaction (OER) catalysts, whereas their oxygen reduction reaction (ORR) performances have not been studied thoroughly. ${ }^{14,15}$ Recently, various approaches such as coreshell morphology, ${ }^{16-18}$ nanostructuring, ${ }^{19-21}$ single-atom catalysts, ${ }^{22,23}$ introduction of atomic defects, ${ }^{24}$ or coupling with support materials ${ }^{9,25-27}$ have been suggested to enhance the intrinsic catalytic activities. Such modified $\mathrm{Mn}-\mathrm{Co}$-based oxides were reported as promising alkaline ORR and OER catalysts $^{24-26,28}$ with activities close to the state-of-the-art Pt and Ir metals. Recently, Zhao et al. reported systematic theoretical results on the ORR/OER activity of layered $3 \mathrm{~d}$ 
transition-metal oxides, oxy-hydroxides, and hydroxides, with several candidates predicted to be active toward ORR and OER. $^{12}$

Noble-metal supports can significantly modify thermodynamic properties of several types of ultrathin oxide films compared to their bulk counterparts. ${ }^{29}$ Furthermore, density functional theory (DFT) calculations predicted that the filmsupport-electrolyte three-phase boundary promotes kinetics of alkaline hydrogen evolution reaction, later also confirmed by experiments. ${ }^{30-33}$ The beneficial role of Au support was also demonstrated for alkaline OER, with improvement reported for thin $\mathrm{CoO}_{x}{ }^{27} \mathrm{NiO}_{x}{ }^{34} \mathrm{CoCeO}_{x}, \mathrm{NiCeO}_{x}{ }^{9}$ and core-shell $\mathrm{CoFeO}_{x}{ }^{18}$ Recent emergence of single-layer cobalt oxide nanoislands supported on gold ${ }^{35}$ established $\mathrm{H}_{2} \mathrm{O}$ catalytic reactivity at the edges of the nanoislands. ${ }^{36}$ Therefore, combined experimental and theoretical results indicate that the stability as well as the activity can be tuned by changing the support materials, prompting a comparative study on the support effects. However, to our knowledge, there has been no theoretical study on the application of supported (oxy-hydro) oxide systems for ORR due to the added computational complexity of extended systems consisting of magnetic metal oxides.

Here, we systematically investigate (oxy-hydro) oxide nanoislands supported on metals using DFT calculations to study the bifunctional effect of supports on the stability and ORR activity of nanoislands. We construct Pourbaix diagrams of the nanoislandlsupport $-\mathrm{H}_{2} \mathrm{O}$ systems to predict their stability under the ORR conditions, evaluate their ORR activity, and discover novel stable and active candidates. In addition, we also perform a correlation analysis to select features of the atomic structure that significantly affect the stability and activity, and propose descriptors through a multivariant linear regression to predict the target properties from readily available quantities.

\section{RESULTS}

Trends in Stabilization Effects of Support Metals. Zeng et al. first demonstrated that the support can significantly stabilize the (oxy-hydro) oxides. ${ }^{29}$ Here, four metal oxides $\left(\mathrm{MO}_{2}, \mathrm{M}=\mathrm{Co}, \mathrm{Fe}, \mathrm{Mn}, \mathrm{Ni}\right)$ and metal oxy-hydroxides $(\mathrm{MOOH})$ in the form of single-layer nanoribbons are supported on three face-centered cubic (FCC) metal supports $\left(\mathrm{Ag}, \mathrm{Au}\right.$, and $\mathrm{Pt}$ ) (Figure 1). ${ }^{35,37,38}$ In all cases, we observed less than $10 \%$ of lattice mismatches between nanoribbons and supports (see Supporting Information, Table S1) which leads to commensurate lattice matching along the [110] direction (Figure 1). We selected the most stable Z(111)-type edge termination for the nanoribbon with the width of three oxide units separated by three FCC metal layers. ${ }^{37}$ As a result, the $(2$ $\times 3)$ nanoribbon is placed onto $(2 \times 6)$ FCC support denoted, hereafter, as nanoislandlsupport. For simplicity, we assume only $0 \%$ (Figure 1a) and 100\% hydroxylation (Figure 1b), while experimentally intermediate levels of hydroxylation are possible. $^{35,37,38}$

To understand the trends of support effects on stabilizing nanoislands, we evaluate the interface formation energy as ${ }^{29}$

$$
E_{\text {interface }}=\left[E_{\mathrm{MO}_{2} \mathrm{H}_{x}+\mathrm{FCC}}-E_{\mathrm{FCC}}-n E_{\mathrm{MO}_{2} \mathrm{H}_{x}}\right] / n
$$

where $E_{\mathrm{MO}_{2} \mathrm{H}_{x}+\mathrm{FCC}}, E_{\mathrm{FCC}}$, and $E_{\mathrm{MO}_{2} \mathrm{H}_{x}}$ are electronic energies of the total system, metal support, and bulk (oxy-hydro) oxide, and $n$ is the number of oxide units in the nanoisland. To
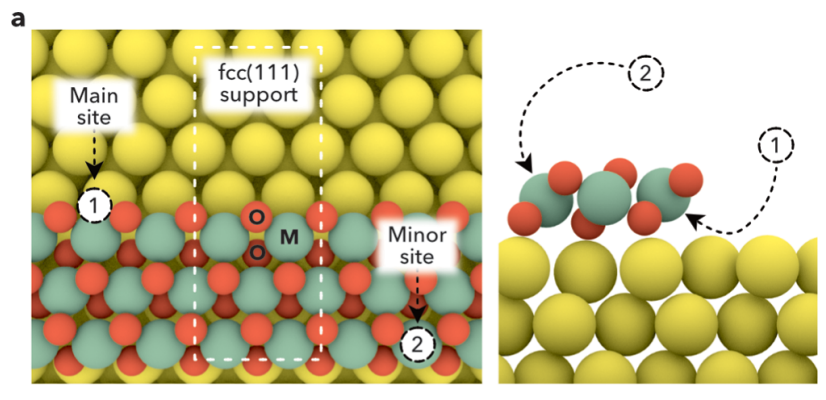

b
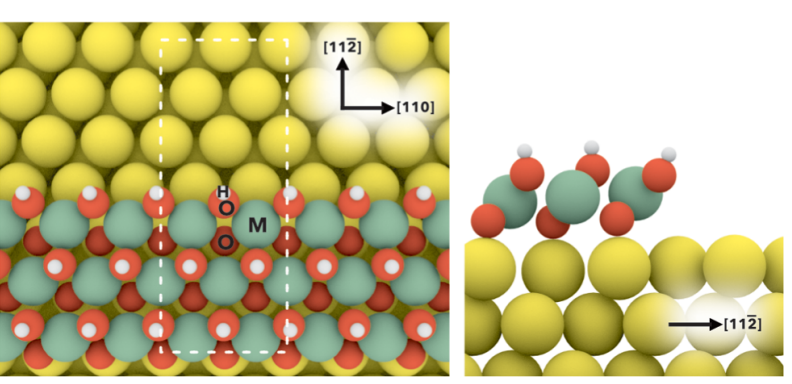

Figure 1. Geometries of nanoislandlsupport systems. Top and side views of (a) oxidelsupport and (b) oxy-hydroxidelsupport. Interfacial main site (1), where adsorbates interact with both support and nanoislands directly, and stand-alone minor site (2), where adsorbates only interact with nanoislands are indicated. Color code: support metals (yellow), nanoisland metals (green), oxygens (red), and hydrogens (white).

calculate bulk electronic energies, we assumed the layered structures to be the most stable for $\mathrm{Fe}$ and $\mathrm{Mn}$ (oxy-hydro) oxides, although goethite $\mathrm{FeOOH}^{39}$ and pyrolusite $\mathrm{MnO}_{2}{ }^{40}$ are slightly more stable than the layered polymorph by a few meV per formula unit (f.u.). ${ }^{39,41,42}$ Importantly, Co and $\mathrm{Ni}$ (oxy-hydro) oxides readily form stable layered structures.

In Figure $2 \mathrm{a}$, we present the calculated $E_{\text {interface }}$ for all nanoislandlsupport systems as a function of supports. Because the $E_{\text {interface }}$ is referenced to the bulk energy of (oxy-hydro) oxides, this quantity is a measure of (de)stabilization of the nanoislands in the presence of support. Generally, we found that the stabilization effects increase as the support changes from $\mathrm{Au}$ to $\mathrm{Ag}$ and to Pt. This finding can be directly linked to oxophilicity of the support metals because of chemical interactions between oxygen atoms in nanoislands and the metal supports. In addition, analysis of the projected density of states of nanoislandlsupport shows that the d-band of the support metal is shifted toward the Fermi level as the support changes from $\mathrm{Ag}$ to $\mathrm{Au}$ to $\mathrm{Pt}$, indicating stronger electronic interactions with nanoislands (Figure S1). Oxides (open symbols) are always more stabilized than oxy-hydroxides (closed symbols), $\mathrm{NiOOH}$ being the only exception. The reason behind this trend is simply because highly oxidized $\mathrm{MO}_{2}$ oxides are much less stable their $\mathrm{MOOH}$ counterparts. On the other hand, the reason for the exception is that $\mathrm{NiOOH}$ tends to be significantly reduced compared to other $\mathrm{MOOH}$. Specifically, the oxidation states of $\mathrm{Ni}$ metals in $\mathrm{NiOOH}$ on all supports were found to be $2+$, while the oxidation states of other $\mathrm{MOOH}$ are combinations of $2+$ and $3+$ (Table S3). Because $\mathrm{NiOOH}$ is exceptionally more reduced, the stabilization trend of $\mathrm{NiO}_{2} / \mathrm{NiOOH}$ is different from other $\mathrm{MO}_{2} / \mathrm{MOOH}$. Remarkably, we notice an almost constant gap between the $E_{\text {interface }}$ energies of oxides and oxy- 

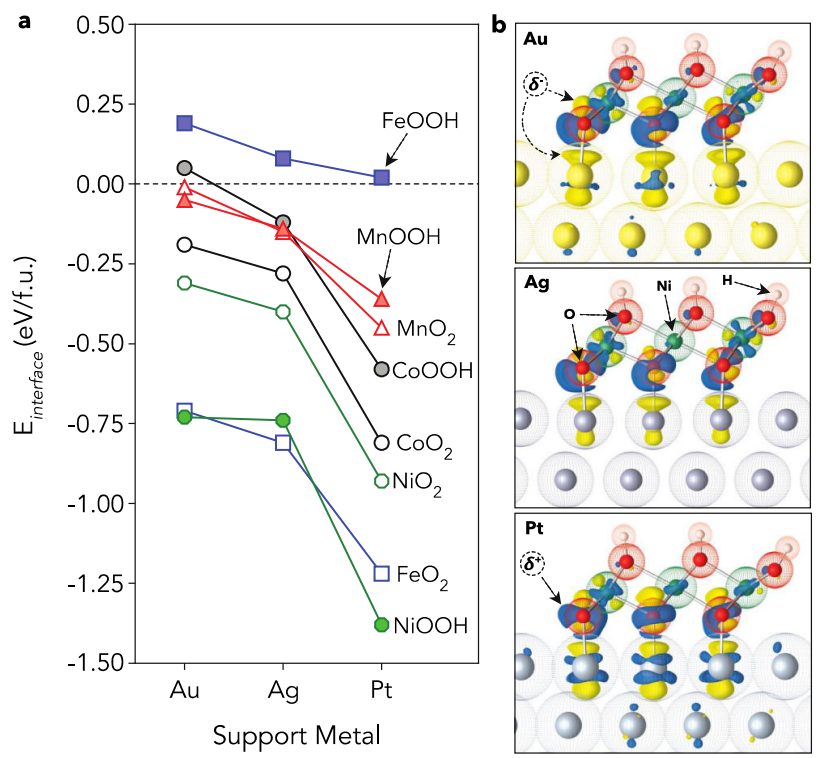

Figure 2. Support effects on the stabilization of nanoislands. (a) Calculated interface formation energy $\left(E_{\text {interface }}\right)$ of nanoislandlsupport systems. (b) Isostructural charge density difference plots of the NiOOHlsupports. The isosurface level is $\delta= \pm 0.005 \mathrm{e} / \AA^{3}$. Yellow (blue) represents charge depletion (accumulation). The dotted spheres represent ionic radii.

hydroxides independently of a metal support (Figure S2). Maintaining the $\mathrm{MO}_{2} / \mathrm{MOOH}$ equilibrium potential at a nearly constant level has major implications on ORR stability as will be discussed below.

To understand electronic interactions between the nanoislands and the supports, we have performed Bader charge analysis and presented the isostructural charge density difference of NiOOHlsupport systems upon adsorption. We have found that in all cases, metal support donates electrons to the nanoislands and the amount of the electron transfer is proportional to stabilization of the interface (Figure S3a). A visualization of reductive charge transfer evidenced that oxygen and metal atoms of the nanoislands gain electrons from supports (Figure $2 \mathrm{~b}$ ). We note that the oxidizing effect of the supports in supported double layer (MO) with reverse $\mathrm{O}-\mathrm{M}$ binding geometry was determined by the electronegativity difference of facing metals. ${ }^{13}$ In our case, the metal supports bind to metal oxide via oxygens which have significantly higher electronegativity than transition metals.

To obtain quantitative insights on the reduction effects of the supports, we have analyzed the change in the local magnetic moment $\left(\mu_{\mathrm{B}}\right)$ of the transition metals in the nanoislands relative to values of their bulk metal (oxy-hydro) oxides (Table S3). ${ }^{9,10,43}$ For example, bulk calculations of Co $+2,+3$, and +4 in $\mathrm{Co}(\mathrm{OH})_{2}, \mathrm{CoOOH}$, and $\mathrm{CoO}_{2}$ at the $\mathrm{PBE}+$ $U$ level of DFT assign the $\mu_{\mathrm{B}}$ of the Co atom to be 2.75 (highspin), 0 (low-spin), and 1.18 (low-spin), respectively, which allows to indirectly identify the oxidation state of the metal. The calculated $\mu_{\mathrm{B}}$ of $2 / 3$ Co atoms in CoOOHIAg is $\sim 2.6$, and $\mu_{\mathrm{B}}$ of $1 / 3$ Co atoms is 0.0 , which correspond to +2 and +3 , respectively, resulting in a net oxidation state of +2.33 . On the other hand, $\mu_{\mathrm{B}}$ of all $\mathrm{Co}$ atoms in $\mathrm{CoOOH} \mathrm{Pt}$ is $\sim 2.6$,
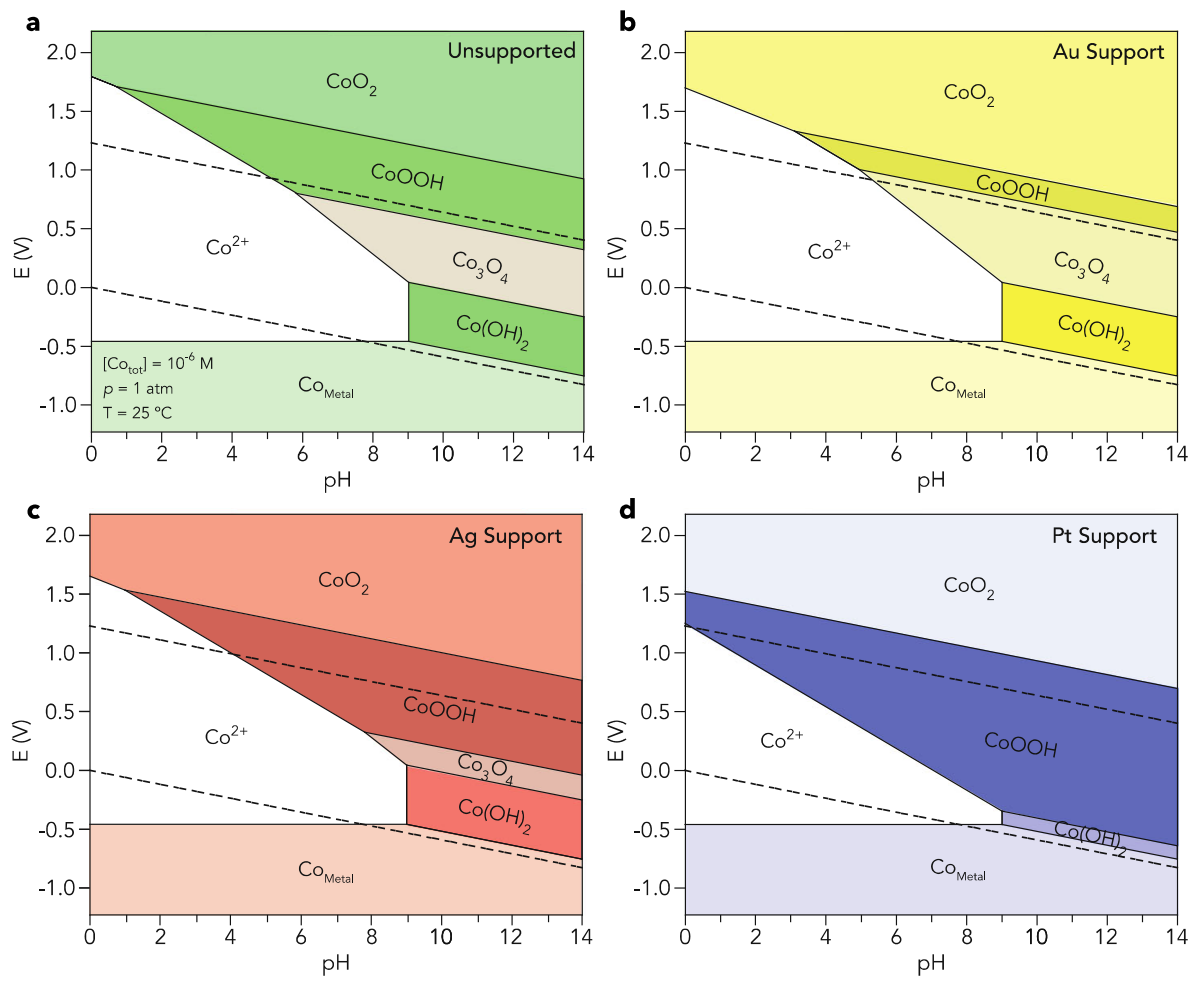

Figure 3. Pourbaix diagrams of (un)supported $\mathrm{Co}-\mathrm{H}_{2} \mathrm{O}$ phases. Diagrams of (a) unsupported, (b) Au-supported, (c) Ag-supported, and (d) Ptsupported $\mathrm{CoO}_{2} / \mathrm{CoOOH}$. The unsupported plot (a) is based on the experimental values of formation free energies of bulk phases (Table S2), and calculated $E_{\text {interface }}$ of $\mathrm{CoO}_{2}$ and $\mathrm{CoOOH}$ were added for each support (from Figure 2a) to construct (b-d). Dashed lines are the equilibrium potentials for oxygen $\left(E_{\mathrm{O}_{2} / \mathrm{H}_{2} \mathrm{O}}=1.23 \mathrm{~V}_{\mathrm{RHE}}\right)$ and hydrogen $\left(E_{\mathrm{H}^{+} / \mathrm{H}_{2}}=0.00 \mathrm{~V}_{\mathrm{RHE}}\right)$ electrochemistry. 

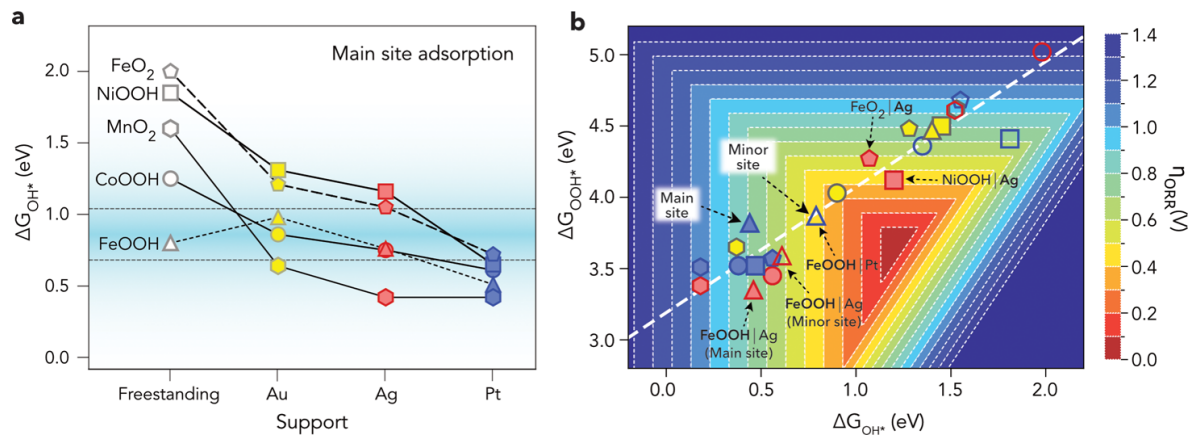

Figure 4. Support effects on the ORR activities. (a) Main-site $\mathrm{OH}^{*}$ binding free energy, $\Delta G_{\mathrm{OH}^{*}}$. The range of optimal $\Delta G_{\mathrm{OH}^{*}}$ is highlighted in blue. $^{2}$ The results for unsupported nanoislands are taken from ref 12. (b) Two-dimensional ORR volcano plot of examined nanoislandlsupport systems plotted as a heat map of calculated $\eta_{\mathrm{ORR}} \mathrm{vs} \Delta G_{\mathrm{OH}^{*}}$ and $\Delta G_{\mathrm{OOH}^{*}}$. Same colors and markers referring to the atomic structures are used for $(\mathrm{a}, \mathrm{b})$. Full and empty symbols correspond to adsorptions at the main site and minor site, respectively. The white dashed line shows a correlation between $\Delta G_{\mathrm{OH}^{*}}$ and $\Delta G_{\mathrm{OOH}^{*}}\left(\Delta G_{\mathrm{OOH}^{*}}=0.88 \Delta G_{\mathrm{OH}^{*}}+3.19 \mathrm{eV}\right)$.

indicating that all $\mathrm{Co}+3$ atoms are reduced to +2 , confirming the electron transfer from the support to the nanoislands. Comparing the oxidation states of $\mathrm{Co}$ in $\mathrm{CoOOH}$ on $\mathrm{Ag}, \mathrm{Au}$, and $\mathrm{Pt}$ as explained above, we have therefore identified that the reducing ability of $\mathrm{Ag}$ and $\mathrm{Au}$ is similar, whereas that of $\mathrm{Pt}$ is comparatively stronger.

Electrochemical Stability Enhancement beyond the Bulk Limits. To investigate the stability of the nanoislands under relevant ORR conditions, we have constructed Pourbaix diagrams of the nanoislandlsupport systems (Figures 3 and S4-S6) by incorporating the effects of noble-metal supports $\left(E_{\text {interface }}\right)$ into the unsupported bulk Pourbaix diagram. From this analysis, we confirm that the difference in $E_{\text {interface }}$ is support-insensitive (Figures 3 and $\mathrm{S} 2$ ), that is, the $\mathrm{MO}_{2}$ / $\mathrm{MOOH}$ equilibrium potential of $\mathrm{M}=\mathrm{Co}, \mathrm{Ni}$, and $\mathrm{Mn}$ for all supports is roughly $1.5,1.3$, and $0.8 \mathrm{~V}_{\mathrm{RHE}}$, respectively. Because oxides $\left(\mathrm{MO}_{2}\right)$ are the most stable phase above the equilibrium potential, we predict $\mathrm{CoO}_{2}$ and $\mathrm{NiO}_{2}$ phases to be irrelevant under ORR conditions (operating potential near $0.8 \mathrm{~V}_{\mathrm{RHE}}{ }^{17}$ ). On the other hand, the $\mathrm{FeO}_{2}$ region dominates and $\mathrm{FeOOH}$ disappears from the Pourbaix diagram on all the metal supports because of significant support-induced stabilization (Figure S4).

The analysis of the Pourbaix diagrams of the nanoislandl support composites allows us to determine the relevant phase to the targeted electrochemical reaction. For instance, the most stable phase of Co nanoislands on $\mathrm{Ag}$ and $\mathrm{Pt}$ supports under the ORR condition $\left(\sim 0.8 \mathrm{~V}_{\mathrm{RHE}}\right)$ is $\mathrm{CoOOH}$ because of the stabilization effects of the support metals $(-0.12$ and -0.58 $\mathrm{eV} /$ f.u., respectively), while $\mathrm{CoOOH}$ on $\mathrm{Au}$ is destabilized by $0.05 \mathrm{eV} /$ f.u., making $\mathrm{Co}_{3} \mathrm{O}_{4}$ most stable at ORR potentials. The ORR activities of related phases determined from the Pourbaix analysis are discussed below.

Activity Enhancement of NanoislandISupport Systems. The effective ORR activity of the nanoislandlsupport systems can be evaluated from the thermodynamics of the associative reaction mechanism ${ }^{2,44}$ (see the Methods section for details). Such $\mathrm{MO}_{2}$ and $\mathrm{MOOH}$ nanoislands feature two types of edge sites. First, there is a unique main site (labeled as (1) in Figure 1) with adsorbates in direct contact with the nanoisland and the support, and where large synergistic interfacial effect is expected., ${ }^{9,45}$ Then, there is a stand-alone minor site (labeled as (2) in Figure 1), which is not in contact with the support and only indirect interactions are expected. For the materials that bind too strongly at the main site, we have subsequently explored binding at the minor site. During the electrochemical process, the $\mathrm{O}^{*}$ or $\mathrm{OH}^{*}$ coverage of active sites is a function of an applied potential and was determined via the surface Pourbaix diagram analysis (Figures S7 and S8). All adsorption geometries and associated energies are available online, ${ }^{46}$ and two examples are illustrated in Figures S9 and S10.

The most important descriptor for the ORR activity is the free energy of $\mathrm{OH}^{*}$ binding $\Delta G_{\mathrm{OH}^{*} \cdot}{ }^{2}$ We have plotted $\Delta G_{\mathrm{OH}^{*}}$ of main site adsorption for the studied noble-metal supports in Figure $4 \mathrm{a}$, and for comparison, we have also included the results for unsupported single-layer (oxy-hydro) oxides from our recent study. ${ }^{12}$ We observe that $\mathrm{OH}^{*}$ binding at all nanoislandlsupport systems is stronger than at unsupported systems ( $\mathrm{FeOOH}$ being the only exception), demonstrating the positive effect of support on the adsorbates at the interfacial main site. Similar to the stabilization trend, we observed gradual strengthening of the $\mathrm{OH}^{*}$ adsorption as the support material changes from $\mathrm{Au}$ to $\mathrm{Ag}$ to $\mathrm{Pt}$ in all cases. Therefore, as discussed above, the activity trends could also be correlated with the oxygen affinity of the support metals because $\mathrm{OH}^{*}$ interacts directly with the nanoisland and the metal support (Figure S9). We note that $\Delta G_{\mathrm{OH}^{*}}$ of unsupported $\mathrm{FeOOH}$ is stronger than that of $\mathrm{FeOOH} \mid \mathrm{Au}$ and $\mathrm{FeOOH} \mid \mathrm{Ag}$, where this exceptional behavior could be originated from the destabilization of $\mathrm{FeOOH}$ on $\mathrm{Ag}$ and $\mathrm{Au}$ (Figure 2a). For nanoislandlsupport systems with too strong $\Delta G_{\mathrm{OH}^{*}}$ at the main site $\left(\Delta G_{\mathrm{OH}^{*}}<0.8 \mathrm{eV}\right)$, we have additionally considered the minor site as active sites (hollow symbols in Figure $4 \mathrm{~b})$. We note that $\Delta G_{\mathrm{OH}^{*}}$ is less correlated with the amount of transferred electrons (Figure S3b), unlike the stabilization of the interface, which is strongly correlated with the amount of transferred electrons. A possible reason behind this observation is that adsorbates interact directly with both the metal support and nanoisland.

The ORR activities of the nanoislandlsupport systems for both the main site and minor site are summarized in Figure $4 \mathrm{~b}$. This plot shows the two-dimensional volcano plot which predicts theoretical ORR overpotential, $\eta_{\text {ORR }}$ (see the Methods section), based on $\Delta G_{\mathrm{OH}^{*}}$ and $\Delta G_{\mathrm{OOH}^{*}}$ energies and $\Delta G_{\mathrm{O}^{*}}=$ $2 \Delta G_{\mathrm{OH}^{*}}$ scaling. ${ }^{2}$ The scaling relation for the main-site adsorption of nanoislandlsupport (white dashed line, $\left.\Delta G_{\mathrm{OOH}^{*}}=0.88 \Delta G_{\mathrm{OH}^{*}}+3.19\right)$ was found to be very similar to the previously reported universal scaling relation for various classes of materials $\left(\Delta G_{\mathrm{OOH}^{*}}=\Delta G_{\mathrm{OH}^{*}}+3.2\right) .{ }^{2,14}$ On the basis 
of this analysis, we discover $\mathrm{CoOOH} / \mathrm{Au}, \mathrm{NiOOH} A \mathrm{Ag}$, and $\mathrm{FeO}_{2} \mid \mathrm{Ag}$ as the active catalyst systems for the ORR with a $\eta_{\mathrm{ORR}}$ of $0.34,0.43$, and $0.58 \mathrm{~V}$, respectively. For the minor-site binding, we find that $\mathrm{CoOOH} / \mathrm{Pt}$ and $\mathrm{FeOOH} \mid \mathrm{Pt}$ to be active with a $\eta_{\text {ORR }}$ of 0.67 and $0.59 \mathrm{~V}$, respectively. However, taking stability requirements into consideration, the most promising candidates for alkaline ORR catalysts are $\mathrm{NiOOH}\left|\mathrm{Ag}, \mathrm{FeO}_{2}\right|$ $\mathrm{Ag}$, and $\mathrm{CoOOH} \mathrm{Pt}$ (see Figures $3 \mathrm{~b}$ and S4-S6). We note that all these candidates are predicted to be as active as the $\mathrm{Pt}$ catalyst with an overpotential $\left(\eta_{\text {ORR }}\right)$ of $\sim 0.50 \mathrm{~V} .{ }^{17}$ Additionally, we have checked the existence of favorable sites, where the dissociative mechanism could play a role. Using the results for unsupported metal oxides, ${ }^{12}$ only the exposed metal-edge bridge sites of $\mathrm{NiOOH}$ have sufficiently low vacancy formation energy to be similar in activity to main and minor sites in the associative mechanism.

Prediction of Activity and Stability Descriptors. For future rational design of nanoislandlsupport catalysts, it is beneficial to find elementary descriptors that predict our target properties, $\Delta G_{\mathrm{OH}^{*}}$ for activity and $E_{\text {interface }}$ for stability, without a need for expensive DFT calculations required for such extended nanostructured systems. In this sense, we have identified various features (Table 1 ) that are easily available

Table 1. Features of the NanoislandlSupport Systems

\begin{tabular}{|c|c|}
\hline abbreviation & description \\
\hline$q_{\mathrm{M}, \mathrm{free}}$ & $\begin{array}{l}\text { Bader charge of the active metal atom of freestanding (oxy- } \\
\text { hydro) oxides }\end{array}$ \\
\hline$\Delta G_{\mathrm{OH}^{*} \text {,free }}$ & $\mathrm{OH}^{*}$ binding free energy of freestanding (oxy-hydro) oxides ${ }^{12}$ \\
\hline$d_{\mathrm{M}}$ & $\begin{array}{l}\text { the number of } \mathrm{d} \text { electrons of the metal in nanoislands from a } \\
\text { formal oxidation state }\end{array}$ \\
\hline$\chi_{\mathrm{M}}$ & electronegativity of the metal in nanoislands \\
\hline$q_{\mathrm{M}, \mathrm{S}}$ & $\begin{array}{l}\text { Bader charge of the main-site metal atom in nanoislands of } \\
\text { nanoislandlsupport systems }\end{array}$ \\
\hline$d_{\mathrm{S}}$ & the number of $d$ electrons of support metals \\
\hline$\chi_{\mathrm{s}}$ & electronegativity of support metals \\
\hline$\Delta G_{\mathrm{OH}^{*}, \mathrm{~S}}$ & $\begin{array}{l}\mathrm{OH}^{*} \text { binding free energy on the (111) surface of support } \\
\text { metals }\end{array}$ \\
\hline$q_{\mathrm{s}}$ & Bader charge of support metals in nanoislandlsupport systems \\
\hline
\end{tabular}

and already reported in the literature, and plotted their relative correlation with our target properties. Figure 5a shows that the electronegativity of the metal in nanoislands $\left(\chi_{\mathrm{M}}\right)$ and $\mathrm{OH}^{*}$ binding free energy of support metals $\left(\Delta G_{\mathrm{OH}^{*}, \mathrm{~S}}\right)$ are the two most correlated features with $\Delta G_{\mathrm{OH}^{*}}$ at the main site, while $\mathrm{OH}^{*}$ binding free energy of freestanding nanoislands $\left(\Delta G_{\mathrm{OH}^{*} \text {,free }}\right)$ and Bader charge of support metals $\left(q_{\mathrm{s}}\right)$ are the two most correlated features with $E_{\text {interface }}$. Therefore, we used $\chi_{\mathrm{M}}$ and $\Delta G_{\mathrm{OH}^{*}, \mathrm{~S}}$ to fit the linear model for $\Delta G_{\mathrm{OH}^{*}}$. In the latter case, however, we used $\Delta G_{\mathrm{OH}^{*}, \mathrm{~S}}$, instead of $q_{\mathrm{S}}$, because using both $\Delta G_{\mathrm{OH}^{*} \text {,free }}$ and $q_{\mathrm{S}}$ is redundant as they are highly correlated with each other $\left(R^{2} \geq 0.80\right.$, see Figure $\left.5 \mathrm{~b}\right)$. The resulting linear models

$$
\begin{aligned}
\Delta G_{\mathrm{OH}^{*}}(\text { lin. reg. })= & -4.32+1.87 \chi_{\mathrm{M}}+1.14 \Delta G_{\mathrm{OH}^{*}, \mathrm{~S}} \\
E_{\text {interface }}(\text { lin. reg. })= & -0.30-0.88 \Delta G_{\mathrm{OH}^{*}, \text { free }} \\
& +0.81 \Delta G_{\mathrm{OH}^{*}, \mathrm{~S}}
\end{aligned}
$$

present simple but effective descriptors to predict $\Delta G_{\mathrm{OH}^{*}}$ and $E_{\text {interface }}$ of the nanoislandlsupport systems, respectively. Figure $5 c, d$ shows that such descriptors could reasonably predict the target values within a mean absolute error of $0.20 \mathrm{eV}$ using only two features in both cases. Notably, $\Delta G_{\mathrm{OH}^{*} \text {,S }}$ plays a significant role in determining both target values, further underlying the bifunctionality of the noble-metal supports on the activity and selectivity, as discussed above.

Lastly, it is convenient that is $\Delta G_{\mathrm{OH}^{*}, \mathrm{~S}}$ is readily available from simple binding energy calculations, which is significantly more cost-effective than the current DFT calculations of extended nanoislandlsupport systems, and $\chi_{\mathrm{M}}$ and $\Delta G_{\mathrm{OH}^{*}}$, free are already tabulated and available online at Catalysishub.org. ${ }^{12}$ Our analysis provides a practical and useful approach to screen new combinations of nanoislandlsupport systems for ORR without expensive DFT calculations. For instance, for highly oxygen-affinitive FCC metals $(\mathrm{Cu}, \mathrm{Ni}, \mathrm{Rh})$, our model predicts significant stabilization of the nanoislands and strengthening of the main-site $\mathrm{OH}^{*}$ binding (Table S4), suggesting that $\mathrm{Cu}, \mathrm{Ni}$, and $\mathrm{Rh}$ are not appropriate metal supports of nanoislands for ORR due to too strong $\mathrm{OH}^{*}$ binding.

\section{CONCLUSIONS}

The bifunctional effect of noble-metal supports on stabilizing (oxy-hydro) oxide nanoislands and hence enhancing ORR activity were demonstrated by using DFT calculations. The stabilization effects introduce new composite phases beyond the intrinsic stability limits of bulk phases. The unique interfacial active sites between supports and nanoislands enhance the binding strength of oxygenated species compared to their unsupported counterparts, discovering $\mathrm{CoOOH} / \mathrm{Pt}$, $\mathrm{NiOOH} \mid \mathrm{Ag}$, and $\mathrm{FeO}_{2} \mid \mathrm{Ag}$ to be active and stable catalysts for alkaline ORR. To generalize such support effects, we have developed predictive descriptors using multivariant linear regression. The combined correlation and linear regression analysis reinforces the finding that oxygen affinity of the support metal plays a key role for both activity and stability. These results provide a theoretical framework for prediction of essential properties of the future nanoislandlsupport catalysts.

\section{METHODS}

Computational Parameters. All electronic structure calculations were performed within GGA-PBE ${ }^{47}$ plus Hubbard- $U$ framework (PBE $+U)$ using projector-augmented wave pseudopotentials ${ }^{48,49}$ as implemented in the VASP code. ${ }^{50,51}$ The Hubbard effective terms $U_{\text {eff }}(\mathrm{Co})=3.32 \mathrm{eV}, U_{\text {eff }}(\mathrm{Fe})=5.3 \mathrm{eV}, U_{\text {eff }}(\mathrm{Mn})=3.9 \mathrm{eV}$, and $U_{\text {eff }}(\mathrm{Ni})=6.2 \mathrm{eV}$ were chosen from the Materials Project database $^{52,53}$ and added to the PBE exchange-correlation functional as proposed by Dudarev et al. ${ }^{54}$

Spin-polarized DFT calculations were performed, and the most stable magnetic structures between ferromagnetic and antiferromagnetic were considered. The plane wave energy cutoff was set to 500 $\mathrm{eV}$, and $15 \AA$ of vacuum was added in the $z$-direction to avoid undesirable interaction between repeating images. All structures contain the $(2 \times 3)$ supercell of the $\mathrm{MO}_{2} / \mathrm{MOOH}$ monolayer $(\mathrm{M}=$ $\mathrm{Co}, \mathrm{Fe}, \mathrm{Mn}, \mathrm{Ni})$ supported on the $(2 \times 6)$ supercell of metals $(\mathrm{Ag}$, $\mathrm{Au}, \mathrm{Pt}$ ) with the bottom two layers fixed to the bulk positions (Figure 1). All structures are sampled by the $(4 \times 1 \times 1)$ Monkhorst-Pack $k$ point mesh. ${ }^{55}$ The convergence criteria for energy (self-consistent iteration) and force (ionic relaxation) were set to be $10^{-4} \mathrm{eV}$ and 0.05 $\mathrm{eV} / \AA ̊$, respectively.

Between the associative $e^{2,44}$ and dissociative $e^{44,56}$ ORR mechanisms, we have only considered the associative reaction mechanism to investigate the ORR catalytic activity of nanoislandlsupport systems. The dissociative mechanism affects only the weakly binding active sites $\left(\Delta G_{\mathrm{OH}^{*}}>0.92 \mathrm{eV}\right)$, and in principle can improve the limitations of $\mathrm{OOH}^{*}$ formation of the associative mechanism, provided that sites 

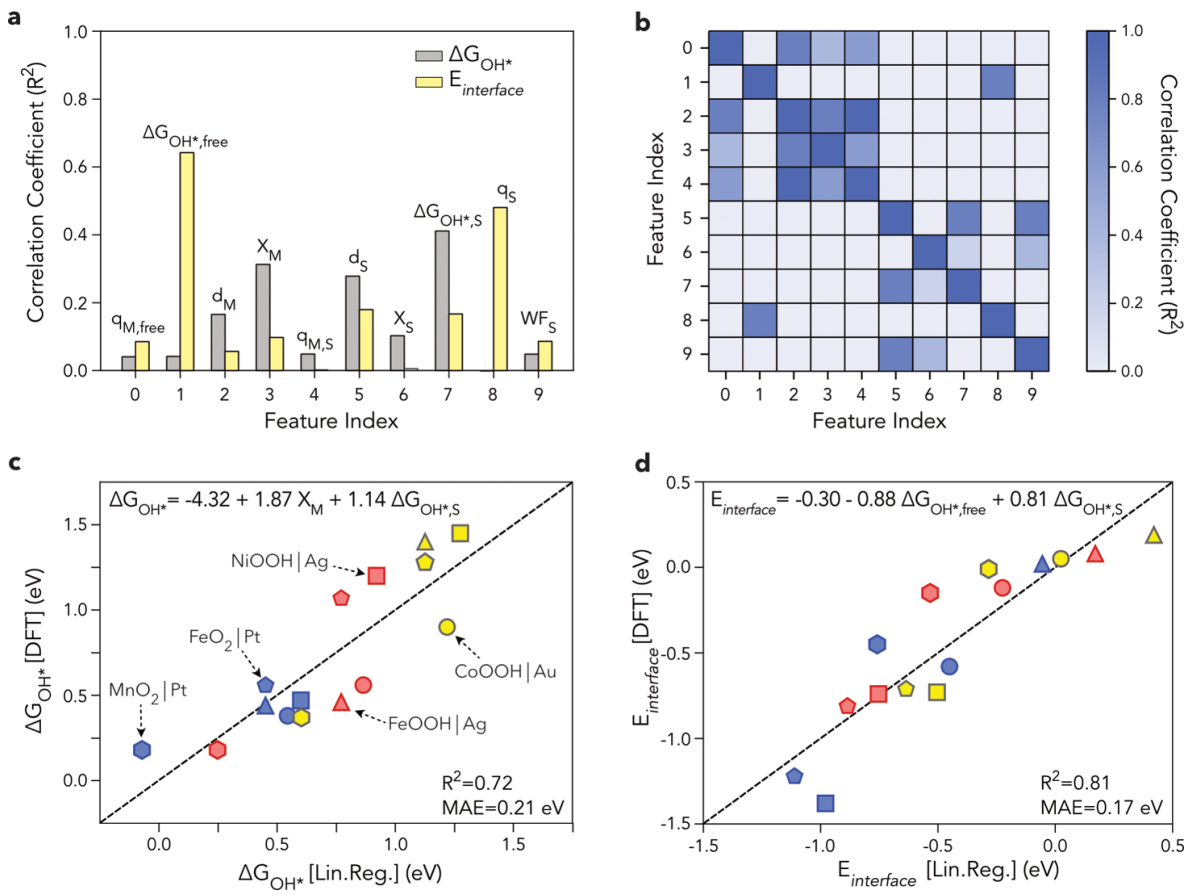

Figure 5. Multivariant linear regression analysis. (a) Correlation coefficient $\left(R^{2}\right)$ of each feature toward the target properties, $\Delta G_{\mathrm{OH}}$ and $E_{\text {interface}}$. (b) Correlation coefficient matrix between the features. Darker color indicates higher correlation between two individual features. Comparison between predicted values from descriptors and calculated values from DFT for (c) $\Delta G_{\mathrm{OH}^{*}}$ and (d) $E_{\text {interface }}$ with symbols defined in Figure 4 .

with favorable oxygen vacancy do exist. The associative mechanism is as follows:

$$
\begin{aligned}
& \mathrm{O}_{2}(\mathrm{~g})+\left(\mathrm{H}^{+}+\mathrm{e}^{-}\right)+* \rightarrow * \mathrm{OOH} \\
& * \mathrm{OOH}+\left(\mathrm{H}^{+}+\mathrm{e}^{-}\right) \rightarrow * \mathrm{O}+\mathrm{H}_{2} \mathrm{O}(\mathrm{l}) \\
& * \mathrm{O}+\left(\mathrm{H}^{+}+\mathrm{e}^{-}\right) \rightarrow{ }^{*} \mathrm{OH} \\
& * \mathrm{OH}+\left(\mathrm{H}^{+}+\mathrm{e}^{-}\right) \rightarrow *+\mathrm{H}_{2} \mathrm{O}(\mathrm{l})
\end{aligned}
$$

The calculated electronic energies were converted into free energies by including free energy corrections for adsorbates and gaseous molecules (Tables S5 and S6). We then used the computational hydrogen electrode method ${ }^{44}$ to take into account the effect of the applied potential on free energy changes, where the chemical potential of the proton-electron pair is set to be equivalent to that of gas-phase $\mathrm{H}_{2}$ in the standard condition, $\left[\mu\left(\mathrm{H}^{+}+\mathrm{e}^{-}\right)=1\right.$ / $\left.2 \mu\left(\mathrm{H}_{2}\right)\right]$. As the potential $U_{\text {elec }}$ versus the reversible hydrogen electrode (RHE) is applied, the chemical potential of the electron is shifted by $-e U_{\text {elec }}$ thus, $\left[\mu\left(\mathrm{H}^{+}+\mathrm{e}^{-}\right)=1 / 2 \mu\left(\mathrm{H}_{2}\right)-e U_{\text {elec }}\right]$. Then, the ORR catalytic activity is determined based on ORR overpotential $\left(\eta_{\text {ORR }}\right)$, where $\eta_{\text {ORR }}=\max \left[\Delta G_{2 a}, \Delta G_{2 b}, \Delta G_{2 c} \Delta G_{2 \mathrm{~d}}\right]_{@ U=1.23 \mathrm{v} \cdot{ }^{2}}$ Additional calculation details can be found in the Supporting Information.

Descriptor Exploration. We selected features from a correlation analysis, where we evaluated all pair-wise correlations between a set of features of the atomic models, as well as correlations with the target values, $\Delta G_{\mathrm{OH}^{*}}$ and $E_{\text {interface }}$. We then utilized Scikit-learn, a Pythonbased machine learning library ${ }^{57}$ to fit a multivariate linear regression model in several dimensions to compare the correlation of DFT calculation resulting with physical properties of the system listed in Table 1.

\section{AUTHOR INFORMATION}

\section{Corresponding Authors}

*E-mail: samiras@stanford.edu (S.S.).

*E-mail: bajdich@slac.stanford.edu (M.B.).

\section{ORCID $\odot$}

Martin H. Hansen: 0000-0003-0818-1515

Samira Siahrostami: 0000-0002-1192-4634

Michal Bajdich: 0000-0003-1168-8616

\section{Notes}

The authors declare no competing financial interest.

All calculated structures with associated adsorption energies are available to download at Catalysis-hub.org. ${ }^{12,46}$ The Jupiter notebook for the linear regression model will be provided upon request to corresponding authors.

\section{ACKNOWLEDGMENTS}

All authors acknowledge the support from the Toyota Research Institute. S.B. acknowledges the support from the Basic Science Research Program through the National Research Foundation of Korea (NRF) funded by the Ministry of Education (NRF-2017R1A6A3A03006971). The authors acknowledge the use of the computer time allocation at the National Energy Research Scientific Computing Center, a DOE Office of the Science User Facility supported by the Office of Science of the U.S. Department of Energy under contract no. DE-AC02-05CH11231. 


\section{REFERENCES}

(1) Hong, W. T.; Risch, M.; Stoerzinger, K. A.; Grimaud, A.; Suntivich, J.; Shao-Horn, Y. the Rational Design of Non-Precious Transition Metal Oxides for Oxygen Electrocatalysis. Energy Environ. Sci. 2015, 8, 1404-1427.

(2) Kulkarni, A.; Siahrostami, S.; Patel, A.; Nørskov, J. K. Understanding Catalytic Activity Trends in the Oxygen Reduction Reaction. Chem. Rev. 2018, 118, 2302-2312.

(3) Frydendal, R.; Paoli, E. A.; Chorkendorff, I.; Rossmeisl, J.; Stephens, I. E. L. Toward an Active and Stable Catalyst for Oxygen Evolution in Acidic Media: Ti-Stabilized $\mathrm{MnO}_{2}$. Adv. Energy Mater. 2015, 5, 1500991.

(4) Seh, Z. W.; Kibsgaard, J.; Dickens, C. F.; Chorkendorff, I.; Nørskov, J. K.; Jaramillo, T. F. Combining Theory and Experiment in Electrocatalysis: Insights into Materials Design. Science 2017, 355, No. eaad4998.

(5) Kim, B. G.; Kim, H.-J.; Back, S.; Nam, K. W.; Jung, Y.; Han, Y.K.; Choi, J. W. Improved Reversibility in Lithium-Oxygen Battery: Understanding Elementary Reactions and Surface Charge Engineering of Metal Alloy Catalyst. Sci. Rep. 2014, 4, 4225.

(6) Paoli, E. A.; Masini, F.; Frydendal, R.; Deiana, D.; Schlaup, C.; Malizia, M.; Hansen, T. W.; Horch, S.; Stephens, I. E. L.; Chorkendorff, I. Oxygen evolution on well-characterized massselected $\mathrm{Ru}$ and $\mathrm{RuO}_{2}$ nanoparticles. Chem. Sci. 2015, 6, 190-196.

(7) Reier, T.; Oezaslan, M.; Strasser, P. Electrocatalytic Oxygen Evolution Reaction (OER) on Ru, Ir, and Pt Catalysts: a Comparative Study of Nanoparticles and Bulk Materials. ACS Catal. 2012, 2, $1765-1772$

(8) Escudero-Escribano, M.; Malacrida, P.; Hansen, M. H.; VejHansen, U. G.; Velazquez-Palenzuela, A.; Tripkovic, V.; Schiotz, J.; Rossmeisl, J.; Stephens, I. E. L.; Chorkendorff, I. Tuning the Activity of Pt Alloy Electrocatalysts by Means of the Lanthanide Contraction. Science 2016, 352, 73-76.

(9) Ng, J. W. D.; García-Melchor, M.; Bajdich, M.; Chakthranont, P.; Kirk, C.; Vojvodic, A.; Jaramillo, T. F. Gold-supported Ceriumdoped $\mathrm{NiOx}$ Catalysts for Water Oxidation. Nat. Energy 2016, 1, 16053.

(10) Friebel, D.; Louie, M. W.; Bajdich, M.; Sanwald, K. E.; Cai, Y.; Wise, A. M.; Cheng, M.-J.; Sokaras, D.; Weng, T.-C.; Alonso-Mori, R.; Davis, R. C.; Bargar, J. R.; Nørskov, J. K.; Nilsson, A.; Bell, A. T. Identification of Highly Active $\mathrm{Fe}$ Sites in $(\mathrm{Ni}, \mathrm{Fe}) \mathrm{OOH}$ for Electrocatalytic Water Splitting. J. Am. Chem. Soc. 2015, 137, 1305-1313.

(11) Doyle, A. D.; Bajdich, M.; Vojvodic, A. Theoretical Insights to Bulk Activity Towards Oxygen Evolution in Oxyhydroxides. Catal. Lett. 2017, 147, 1533-1539.

(12) Zhao, Z.; Schlexer, P.; Kulkarni, A.; Bajdich, M.; Nørskov, J. K. Trends in Electrochemical Oxygen Activities of Nanostructured Layered Oxy/hydroxides. https://www.catalysis-hub.org/ publications/ZhaoTrends2018, to be submitted (accessed on Dec $24,2018)$.

(13) Plessow, P. N.; Bajdich, M.; Greene, J.; Vojvodic, A.; AbildPedersen, F. Trends in the Thermodynamic Stability of Ultrathin Supported Oxide Films. J. Phys. Chem. C 2016, 120, 10351-10360.

(14) Man, I. C.; Su, H.-Y.; Calle-Vallejo, F.; Hansen, H. A.; Martínez, J. I.; Inoglu, N. G.; Kitchin, J.; Jaramillo, T. F.; Nørskov, J. K.; Rossmeisl, J. Universality in Oxygen Evolution Electrocatalysis on Oxide Surfaces. ChemCatChem 2011, 3, 1159-1165.

(15) McCrory, C. C. L.; Jung, S.; Peters, J. C.; Jaramillo, T. F. Benchmarking Heterogeneous Electrocatalysts for the Oxygen Evolution Reaction. J. Am. Chem. Soc. 2013, 135, 16977-16987.

(16) Back, S.; Jung, Y. Importance of Ligand Effects Breaking the Scaling Relation for Core-Shell Oxygen Reduction Catalysts. Chem CatChem 2017, 9, 3173-3179.

(17) Greeley, J.; Stephens, I. E. L.; Bondarenko, A. S.; Johansson, T. P.; Hansen, H. A.; Jaramillo, T. F.; Rossmeisl, J.; Chorkendorff, I.; Nørskov, J. K. Alloys of Platinum and Early Transition Metals as Oxygen Reduction Electrocatalysts. Nat. Chem. 2009, 1, 552-556.
(18) Strickler, A. L.; Escudero-Escribano, M.; Jaramillo, T. F. CoreShell Au@Metal-Oxide Nanoparticle Electrocatalysts for Enhanced Oxygen Evolution. Nano Lett. 2017, 17, 6040-6046.

(19) Wang, D.; Yu, Y.; Xin, H. L.; Hovden, R.; Ercius, P.; Mundy, J. A.; Chen, H.; Richard, J. H.; Muller, D. A.; DiSalvo, F. J.; Abruña, H. D. Tuning Oxygen Reduction Reaction Activity via Controllable Dealloying: a Model Study of Ordered $\mathrm{Cu} 3 \mathrm{Pt} / \mathrm{C}$ Intermetallic Nanocatalysts. Nano Lett. 2012, 12, 5230-5238.

(20) Jiang, K.; Shao, Q.; Zhao, D.; Bu, L.; Guo, J.; Huang, X. Phase and Composition Tuning of 1D Platinum-Nickel Nanostructures for Highly Efficient Electrocatalysis. Adv. Funct. Mater. 2017, 27, 1700830.

(21) Chattot, R.; Asset, T.; Bordet, P.; Drnec, J.; Dubau, L.; Maillard, F. Beyond Strain and Ligand Effects: Microstrain-Induced Enhancement of the Oxygen Reduction Reaction Kinetics on Various $\mathrm{PtNi} / \mathrm{C}$ Nanostructures. ACS Catal. 2016, 7, 398-408.

(22) Back, S.; Kulkarni, A. R.; Siahrostami, S. Single Metal Atoms Anchored in Two-Dimensional Materials: Bifunctional Catalysts for Fuel Cell Application. ChemCatChem 2018, 10, 3034-3039.

(23) Yang, S.; Kim, J.; Tak, Y. J.; Soon, A.; Lee, H. Single-Atom Catalyst of Platinum Supported on Titanium Nitride for Selective Electrochemical Reactions. Angew. Chem., Int. Ed. 2015, 55, 20582062.

(24) Cheng, F.; Zhang, T.; Zhang, Y.; Du, J.; Han, X.; Chen, J. Enhancing Electrocatalytic Oxygen Reduction on $\mathrm{MnO} 2$ with Vacancies. Angew. Chem., Int. Ed. 2013, 52, 2474-2477.

(25) Liang, Y.; Wang, H.; Diao, P.; Chang, W.; Hong, G.; Li, Y.; Gong, M.; Xie, L.; Zhou, J.; Wang, J.; Regier, T. Z.; Wei, F.; Dai, H. Oxygen Reduction Electrocatalyst based on Strongly Coupled Cobalt Oxide Nanocrystals and Carbon Nanotubes. J. Am. Chem. Soc. 2012, 134, 15849-15857.

(26) Liang, Y.; Wang, H.; Zhou, J.; Li, Y.; Wang, J.; Regier, T.; Dai, H. Covalent Hybrid of Spinel Manganese-Cobalt Oxide and Graphene as Advanced Oxygen Reduction Electrocatalysts. J. Am. Chem. Soc. 2012, 134, 3517-3523.

(27) Yeo, B. S.; Bell, A. T. Enhanced Activity of Gold-Supported Cobalt Oxide for the Electrochemical Evolution of Oxygen. J. Am. Chem. Soc. 2011, 133, 5587-5593.

(28) Gorlin, Y.; Jaramillo, T. F. A Bifunctional Nonprecious Metal Catalyst for Oxygen Reduction and Water Oxidation. J. Am. Chem. Soc. 2010, 132, 13612-13614.

(29) Zeng, Z.; Chang, K.-C.; Kubal, J.; Markovic, N. M.; Greeley, J. Stabilization of ultrathin (hydroxy)oxide films on transition metal substrates for electrochemical energy conversion. Nat. Energy 2017, 2, 17070 .

(30) Subbaraman, R.; Tripkovic, D.; Strmcnik, D.; Chang, K.-C.; Uchimura, M.; Paulikas, A. P.; Stamenkovic, V.; Markovic, N. M. Enhancing Hydrogen Evolution Activity in Water Splitting by Tailoring Li+-Ni(OH)2-Pt Interfaces. Science 2011, 334, 1256-1260.

(31) Strmcnik, D.; Uchimura, M.; Wang, C.; Subbaraman, R.; Danilovic, N.; van der Vliet, D.; Paulikas, A. P.; Stamenkovic, V. R.; Markovic, N. M. Improving the Hydrogen Oxidation Reaction Rate by Promotion of Hydroxyl Adsorption. Nat. Chem. 2013, 5, 300.

(32) Danilovic, N.; Subbaraman, R.; Strmcnik, D.; Chang, K.-C.; Paulikas, A. P.; Stamenkovic, V. R.; Markovic, N. M. Enhancing the Alkaline Hydrogen Evolution Reaction Activity through the Bifunctionality of $\mathrm{Ni}(\mathrm{OH}) 2 /$ Metal Catalysts. Angew. Chem. 2012, $124,12663-12666$.

(33) Strmcnik, D.; Lopes, P. P.; Genorio, B.; Stamenkovic, V. R.; Markovic, N. M. Design Principles for Hydrogen Evolution Reaction Catalyst Materials. Nano Energy 2016, 29, 29-36.

(34) Yeo, B. S.; Bell, A. T. In situ Raman Study of Nickel Oxide and Gold-supported Nickel Oxide Catalysts for the Electrochemical Evolution of Oxygen. J. Phys. Chem. C 2012, 116, 8394-8400.

(35) Walton, A. S.; Fester, J.; Bajdich, M.; Arman, M. A.; Osiecki, J.; Knudsen, J.; Vojvodic, A.; Lauritsen, J. V. Interface Controlled Oxidation States in Layered Cobalt Oxide Nanoislands on Gold. ACS Nano 2015, 9, 2445-2453. 
(36) Fester, J.; García-Melchor, M.; Walton, A. S.; Bajdich, M.; Li, Z.; Lammich, L.; Vojvodic, A.; Lauritsen, J. V. Edge Reactivity and Water-assisted Dissociation on Cobalt Oxide Nanoislands. Nat. Commun. 2017, 8, 14169.

(37) Goniakowski, J.; Giordano, L.; Noguera, C. Polarity Compensation in Low-dimensional Oxide Nanostructures: The Case of Metal-Supported MgO Nanoribbons. Phys. Rev. B: Condens. Matter Mater. Phys. 2013, 87, 035405.

(38) Fester, J.; Bajdich, M.; Walton, A. S.; Sun, Z.; Plessow, P. N.; Vojvodic, A.; Lauritsen, J. V. Comparative Analysis of Cobalt Oxide Nanoisland Stability and Edge Structures on Three Related Noble Metal Surfaces: $\mathrm{Au}(111), \mathrm{Pt}(111)$ and $\mathrm{Ag}(111)$. Top. Catal. 2016, 60, 503-512.

(39) Mazeina, L.; Deore, S.; Navrotsky, A. Energetics of Bulk and Nano-Akaganeite, $\beta$-FeOOH: Enthalpy of Formation, Surface Enthalpy, and Enthalpy of Water Adsorption. Chem. Mater. 2006, $18,1830-1838$.

(40) Fritsch, S.; Post, J. E.; Suib, S. L.; Navrotsky, A. Thermochemistry of Framework and Layer Manganese Dioxide related Phases. Chem. Mater. 1998, 10, 474-479.

(41) Kitchaev, D. A.; Peng, H.; Liu, Y.; Sun, J.; Perdew, J. P.; Ceder, G. Energetics of $\mathrm{MnO}_{2}$ Polymorphs in Density Functional Theory. Phys. Rev. B 2016, 93, 045132.

(42) Curtarolo, S.; Morgan, D.; Ceder, G. Accuracy of Ab Initio Methods in Predicting the Crystal Structures of Metals: A Review of 80 Binary Alloys. Calphad 2005, 29, 163-211.

(43) Bajdich, M.; García-Mota, M.; Vojvodic, A.; Nørskov, J. K.; Bell, A. T. Theoretical Investigation of the Activity of Cobalt Oxides for the Electrochemical Oxidation of Water. J. Am. Chem. Soc. 2013, 135, 13521-13530.

(44) Nørskov, J. K.; Rossmeisl, J.; Logadottir, A.; Lindqvist, L.; Kitchin, J. R.; Bligaard, T.; Jónsson, H. Origin of the Overpotential for Oxygen Reduction at a Fuel-Cell Cathode. J. Phys. Chem. B 2004, 108, 17886-17892.

(45) Back, S.; Kim, J.-H.; Kim, Y.-T.; Jung, Y. Bifunctional Interface of $\mathrm{Au}$ and $\mathrm{Cu}$ for Improved $\mathrm{CO} 2$ Electroreduction. ACS Appl. Mater. Interfaces 2016, 8, 23022-23027.

(46) https://www.catalysis-hub.org/publications/ BackPrediction 2018 (accessed on Dec 24, 2018).

(47) Perdew, J. P.; Burke, K.; Ernzerhof, M. Generalized Gradient Approximation Made Simple. Phys. Rev. Lett. 1996, 77, 3865.

(48) Blöchl, P. E. Projector Augmented-wave Method. Phys. Rev. B: Condens. Matter Mater. Phys. 1994, 50, 17953.

(49) Kresse, G.; Joubert, D. From Ultrasoft Pseudopotentials to the Projector Augmented-wave Method. Phys. Rev. B: Condens. Matter Mater. Phys. 1999, 59, 1758.

(50) Kresse, G.; Furthmüller, J. Efficiency of Ab-initio Total Energy Calculations for Metals and Semiconductors using a Plane-wave Basis Set. Comput. Mater. Sci. 1996, 6, 15-50.

(51) Kresse, G.; Hafner, J. Ab initiomolecular dynamics for liquid metals. Phys. Rev. B: Condens. Matter Mater. Phys. 1993, 47, 558.

(52) Wang, L.; Maxisch, T.; Ceder, G. Oxidation Energies of Transition Metal Oxides within the GGA+ U Framework. Phys. Rev. B: Condens. Matter Mater. Phys. 2006, 73, 195107.

(53) Jain, A.; Hautier, G.; Ong, S. P.; Moore, C. J.; Fischer, C. C.; Persson, K. A.; Ceder, G. Formation Enthalpies by Mixing GGA and GGA+ U Calculations. Phys. Rev. B: Condens. Matter Mater. Phys. 2011, 84, 045115.

(54) Dudarev, S. L.; Botton, G. A.; Savrasov, S. Y.; Humphreys, C. J.; Sutton, A. P. Electron-energy-loss spectra and the structural stability of nickel oxide: An LSDA+U study. Phys. Rev. B: Condens. Matter Mater. Phys. 1998, 57, 1505.

(55) Monkhorst, H. J.; Pack, J. D. Special Points for Brillouin-zone Integrations. Phys. Rev. B: Solid State 1976, 13, 5188.

(56) Gu, X.-K.; Carneiro, J. S. A.; Samira, S.; Das, A.; Ariyasingha, N. M.; Nikolla, E. Efficient Oxygen Electrocatalysis by Nanostructured Mixed-Metal Oxides. J. Am. Chem. Soc. 2018, 140, 8128.

(57) Pedregosa, F.; Varoquaux, G.; Gramfort, A.; Michel, V.; Thirion, B.; Grisel, O.; Blondel, M.; Prettenhofer, P.; Weiss, R.;
Dubourg, V. Scikit-learn: Machine Learning in Python. J. Mach. Learn. Res. 2011, 12, 2825-2830. 